\title{
TEMPERATURNI OBRAT V HRIBOVITI SLOVENIJI
}

\author{
Igor Žiberna*
}

Izvleček

UDK 551.524(497.4)

Prispevek obravnava pojav temperaturnega obrata $v$ hriboviti Sloveniji, tipe temperaturnih obratov, njihove višine in razporeditev preko leta. Posebej so obravnavani pojavi temperaturnega obrata $v$ Ljubljanski in Bovški kotlini ter v Dravski dolini.

Ključne besede: temperaturni obrat, klimatogeografija, Slovenija.

TEMPERATURE INVERSION IN MID-ALTITUDE REGIONS OF SLOVENIA

\section{Abstract}

The article treats the phenomenon of temperature inversions in the mountainous Slovenia, the types of temperature inversons, their altitudes and disposition over the year. Especially are treated the phenomena of temperature inversions in the Ljubljana and Bovec basins and in the Drava valley.

Key words: temperature inverion, climatogeography, Slovenia.

\footnotetext{
* Dr., univ. doc., Oddelek za geografijo, Pedagoška fakulteta, Koroška 160, 1000 Maribor,
} Slovenija. 


\section{UVOD}

Temperaturni obrat je pojav, pri katerem temperatura zraka z višino narašča, namesto da bi padala (Encikopedija Slovenije, 1990). V univerzitetni učbeniški literaturi (Šegota, 1989; Barry, 1992; Heyer, 1993; Schönwiese, 1994) se temperaturna temperaturni obrat najpogosteje deli na štiri tipe:

- prizemni temperaturni obrat, ki se pojavlja v nočnem času zaradi specifične energijske bilance prizemne plasti zraka,

- frontalni temperaturni obrat, ki se pojavlja v večjih višinah na meji dveh zračnih mas ob prehodu fronte,

- $\quad$ subsidenčni ali anticiklonalni temperaturni obrat, ki se pojavlja zaradi razlik $\mathrm{v}$ adiabatnem segrevanju spuščajočega se zraka v anticiklonu.

- višinski temperaturni obrat, ki nastane na meji dveh zračnih mas, ki se relativno gibljeta $\mathrm{z}$ različnimi hitrostmi.

Pojav prizemnega temperaturnega obrata lahko krepi tudi relief, saj se zaradi stekanja hladnega zraka na dno dolin in kotlin v energijski bilanci pojavi še advektivni člen (Hočevar, Petkovšek, 1995). Dotok hladnega zraka z okoliških pobočij povzroča dodatni padec temperature zraka na dnu dolin in kotlin. Kot eden od rezultatov teh procesov je tudi pojav termalnega pasu (Gams, 1996).

Temperaturni obrat je glede na zelo razgiban relief v Sloveniji zelo pogost pojav. Kljub temu pa bi bilo zelo posplošeno trditi, da se intenzivnost, višina in letni režim v popolnosti ujemajo $\mathrm{v}$ vseh dolinah. Prej bi lahko dejali, da je zlasti glede radiacijskega temperaturnega obrata vsaka dolina enkratna.

Prispevek govori le o vzorčnih analizah temperaturnega obrata v Ljubljanski in Bovški kotlini ter Dravski dolini. V prvih dveh primerih smo analizirali srednje in ekstremne mesečne temperature meteoroloških postaj na različnih višinah in na ta način želeli ugotoviti intenzivnost temperaturnega obrata in njihov letni režim pojavljanja. V Ljubljanski kotlini in Dravski dolini smo z radiosondažnimi in lastnimi meritvami želeli ugotoviti, na kateri višini se pojavlja temperaturni obrat in kakšen je njen izvor.

Pri podatkih smo se naslonili na podatke objavljene v Klimatografiji Slovenije (temperature zraka) in na radiosondažne meritve, ki se že nekaj let izvajajo na meteorološki postaji Ljubljana - Bežigrad. Z njimi lahko dobimo podatke o različnih meteoroloških parametrih za celotno plast troposfere. 
Pri analizi temperaturnega obrata v Dravski dolini smo uporabili podatke, ki so jih izmerili študentje geografije 1.letnika pozimi 1994/1995 v okviru vaj iz klimatogeografije.

\section{TEMPERATURNI OBRAT V LJUBLJANSKI KOTLINI}

Za analizo spreminjanja temperature $\mathrm{z}$ višino $\mathrm{v}$ širšem območju Ljubljanske kotline smo izbrali šest meteoroloških postaj, za katere obstajajo temperaturni podatki za obdobje 1961-1990: Lipe, Šmarna gora, Planina pod Golico, Dom na Komni, Krvavec in Kredarica. Izbor meteoroloških postaj ni posrečen, je pa glede na obstoječo mrežo meteoroloških postaj edini možen. Za značilno meteorološko postajo na dnu Ljubljanske kotline nalašč nismo izbrali meteorološke postaje LjubljanaBežigrad, saj ta zaradi učinka toplotnega otoka v Ljubljani ne bi prikazovala realnega povprečnega stanja na dnu Ljubljanske kotline ${ }^{1}$. Žal je mreža postaj preredka, zato na podlagi teh podatkov ne moremo natančno ugotoviti, na kateri višini se pojavlja temperaturni obrat in kakšne so na tej višini temperaturne razlike. Prav tako smo zanemarili mikrolokacijo, predvsem ekspozicijo opazovalnega prostora, ki tudi lahko vpliva na temperaturne razmere.

S tabele 1, ki prikazuje temperaturne spremembe srednjih mesečnih temperatur nad Ljubljansko kotlino, opazimo, da je temperaturni obrat najmočnejši v zimskih mesecih (december, januar, deloma februar), ko so srednje mesečne temperature na meteorološki postaji Šmarna gora za 0,3 do $0,5^{\circ} \mathrm{C}$ višje od tistih v Lipah. V ostalih mesecih temperaturni obrat ni tako močan, čeprav so temperaturne razlike v 400metrskem pasu na splošno majhne. Da se temperaturni obrat pojavlja tudi v poletnih mesecih je razvidno iz razmeroma majhnega temperaturnega gradienta. Temperaturni obrat, nakazan $\mathrm{v}$ manjših temperaturnih gradientih, je ponovno pogost $\mathrm{v}$ mesecu oktobru, kar ne preseneča, saj se takrat pogosto pojavljajo anticiklonalni vremenski tipi, ki dajejo dobro osnovo za temperaturni obrat ${ }^{2}$.

$\mathrm{V}$ vrednostih o povprečnih mesečnih temperaturah so že zajete srednje terminske temperature, ki bi lahko najbolje pokazale dnevni režim obrata. Poglejmo si zato, kako so $\mathrm{z}$ višino razporejene srednje mesečne minimalne in srednje mesečne maksimalne temperature. Ob predpostavki, da se minimalne temperature praviloma

\footnotetext{
${ }^{1}$ Primerjava temperatur med meteorološkima postajama Ljubljana - Bežigrad in Lipe (slednja se nahaja na Ljubljanskem barju) kaže, da ima bežigrajska postaja za $1,0^{\circ} \mathrm{C}$ višjo srednjo letno temperaturo, za $0,4^{\circ} \mathrm{C}$ višjo srednjo letno maksimalno in kar za $1,8^{\circ} \mathrm{C}$ višjo srednjo letno minimalno temperaturo. Razlike po posameznih mesecih so seveda še višje.

${ }^{2}$ Po Hočevarju (1966) se anticiklonalni vremenski tipi v oktobru v povprečju pojavljajo vsak drugi dan.
} 
pojavljajo $\mathrm{v}$ jutranjem času, maksimalne pa zgodaj popoldne, lahko $\mathrm{v}$ grobem sklepamo, kaj se dogaja s temperaturnim obratom čez dan.

Slika 1 kaže, da se pri srednjih mesečnih minimalnih temperaturah temperaturni obrat pojavlja $\mathrm{v}$ vseh mesecih $\mathrm{v}$ letu. Zanimivo pa je, da je najinenzivnejša $\mathrm{v}$ pomladanskih in poletnih mesecih in ne pozimi, kot bi sprva lahko sklepali. Pomladi in poleti so minimalne temperature na Šmarni gori za skoraj $2^{\circ} \mathrm{C}$ višje od tistih na dnu Ljubljanske kotline, pozimi pa znaša ta razlika $1,3^{\circ} \mathrm{C}$. V jutranjem času se med avgustom in oktobrom pojavlja še ena inverzna plast na višini od 1200 do $1500 \mathrm{~m}$, vendar ni tako izrazita. O vzrokih za ta višinski temperaturni obrat bi težko govorili, dejstvo pa je, da $\mathrm{v}$ tem primeru ne gre za subsidenčno inverzijo, saj bi se v nasprotnem ta morala opaziti tudi pri vertikalni razporeditvi srednjih maksimalnih temperatur.

Višinska razporeditev srednjih mesečnih maksimalnih temperatur (tabela 1) kaže, da se temperaturni obrat $v$ prizemni plasti popoldne pojavlja redko. Še najizrazitrejša je v decembru, ko je tudi v zgodnjem popoldnevu temperatura zraka na Šmarni gori za $0,2^{\circ} \mathrm{C}$ višja od tiste $\mathrm{v}$ Lipah. $\mathrm{V}$ ostalih mesecih je temperaturni gradient nad Ljubljansko kotlino normalen. $\mathrm{K}$ decembrskemu temperaturnemu obratu botruje megla ali nizka oblačnosti na dnu Ljubljanske kotline, ki lahko vztraja tudi ves dan, medtem ko so višje lege obsijane s Soncem.

Oglejmo si še pogostost pojavljanja obrata nad Ljubljansko kotlino po mesecih. Za vzorec smo uporabili podatke radiosondažnih meritev nad Ljubljansko kotlino v letu 1996. Rezultati kažejo, da se je v tem letu od skupaj 350 opravljenih meritev v kar 159 primerih (ali v 45,4 \% vseh meritev) pojavila katera od oblik obrata. Najpogosteje se je pojavljala temperaturni obrat v decembru (76,7 \% vseh meritev), juliju $(64,5 \%)$ in oktobru. V decembru se je od vseh omenjenih inverzij najpogosteje pojavljala subsidenčna temperaturni obrat (v $65 \%$ vseh meritev tega meseca). Ta se je najpogosteje pojavljala na višinah med 800 in $1800 \mathrm{~m}$.

\section{TEMPERATURNI OBRAT V BOVŠKI KOTLINI}

Pri analizi temperaturnega obrata $\mathrm{v}$ Bovški kotlini smo se naslonili na podatke o srednjih mesečnih in srednjih mesečnih ekstremnih temperaturah za meteorološke postaje Bovec (452 m), Krn (910 m), Dom na Komni (1520 m) in Kredarica (2514 $\mathrm{m})$.

Analiza srednjih mesečnih temperatur zraka ne kaže na izrazit pojav temperaturnega obrata. Še najmanjši, a še vedno negativni temperaturni gradienti se pojavljajo v decembru, ko je Krn, ki leži 460 m nad Bovcem, le za desetinko stopinjo Celzija hladnejši, in v januarju. Na podlagi tega lahko sklepamo, da se temperaturni obrat sicer pojavlja, vendar je zakrit v povprečnih podatkih. Temperaturne razlike 
med Bovcem in Krnom so majhne tudi v oktobru $\left(1,2^{\circ} \mathrm{C}\right)$ in novembru $\left(0,9^{\circ} \mathrm{C}\right)$ (tabela 2).

Razlike v srednjih minimalnih mesečnih temperaturah v Bovški kotlini kažejo na reden pojav inverzije med avgustom in januarjem. Največje temperaturne razlike med Bovcem in Krnom so v decembru, ko je slednji za $0,7^{\circ} \mathrm{C}$ toplejši od Bovca (2). V avgustu in septembru je Krn toplejši od Bovca le za 0,3 oz. $0,4^{\circ} \mathrm{C}$.

Podobno kot v Ljubljnski kotlini, se temperaturni obrat pojavlja tudi v Bovški kotlini v zgodnje popoldanskem času, ko so najpogosteje izmerjene maksimalne dnevne temperature, redek pojav (tabela 2). Temperaturni gradienti so $\mathrm{v}$ vseh mesecih negativni. Še najmanjše razlike med Bovcem in Krnom se pojavljajo v decembru, ko znašajo $0,6^{\circ} \mathrm{C}$. Sklepamo torej lahko, da se temperaturni obrat v decembru občasno lahko zadrži tudi ves dan.

Temperaturni obrat v Bovški kotlini torej ni tako izrazit kot v Ljubljanski kotlini, iz klimatskih podatkov pa lahko sklepamo, da je pogostejši v zimskih mesecih, ko lahko traja ves dan. Seveda pa bi take splošne ocene bilo treba podrobneje analizirati z meritvami na terenu.

\section{TEMPERATURNI OBRAT V DRAVSKI DOLINI}

Na območju Dravske doline je mreža meteoroloških postaj žal preredka, da bi lahko podrobneje analizirali višinsko razporeditev srednjih mesečnih temperatur. Za določitev temperaturnih profilov smo zato opravljali terenske meritve. V ta namen so študentje 1. letnika geografije novembra in decembra leta 1994 s pomočjo žičnice opravljali meritve temperatur med Razvanjem (spodnja postaja pohorske žičnice) in Bolfenkom (zgornja postaja pohorske žičnice). Temperaturo zraka so merili z digitalnim termometrom vsakih deset sekund. 
Tabela 1: Temperaturni obrat v Ljubljanski kotlini
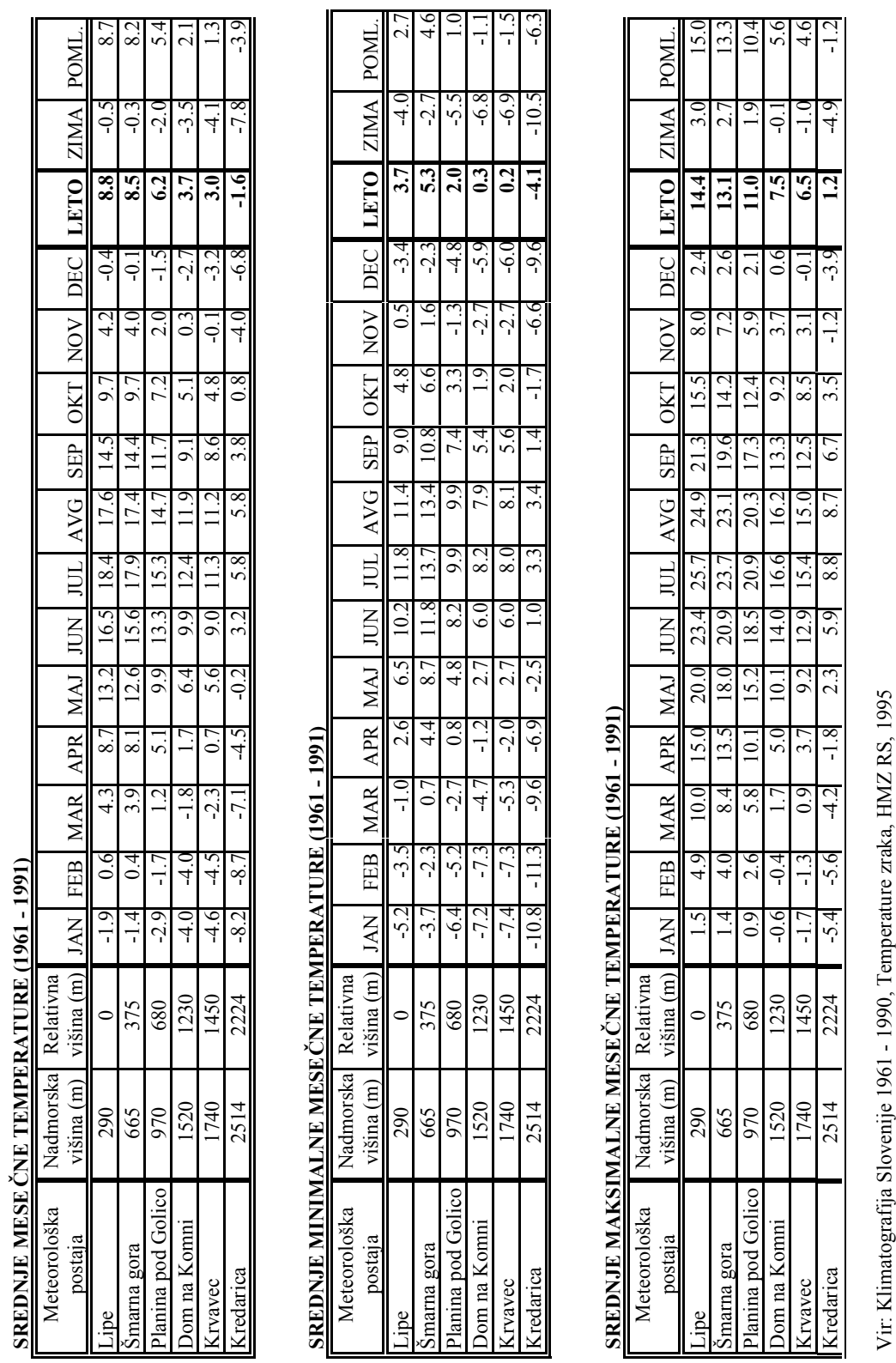
Tabela 2: Temperaturni obrat v Bovški kotlini

Slika 3: Temperaturni profil Radvanje - Bellevue (povprečje meritev v novembru in decembru 1994)

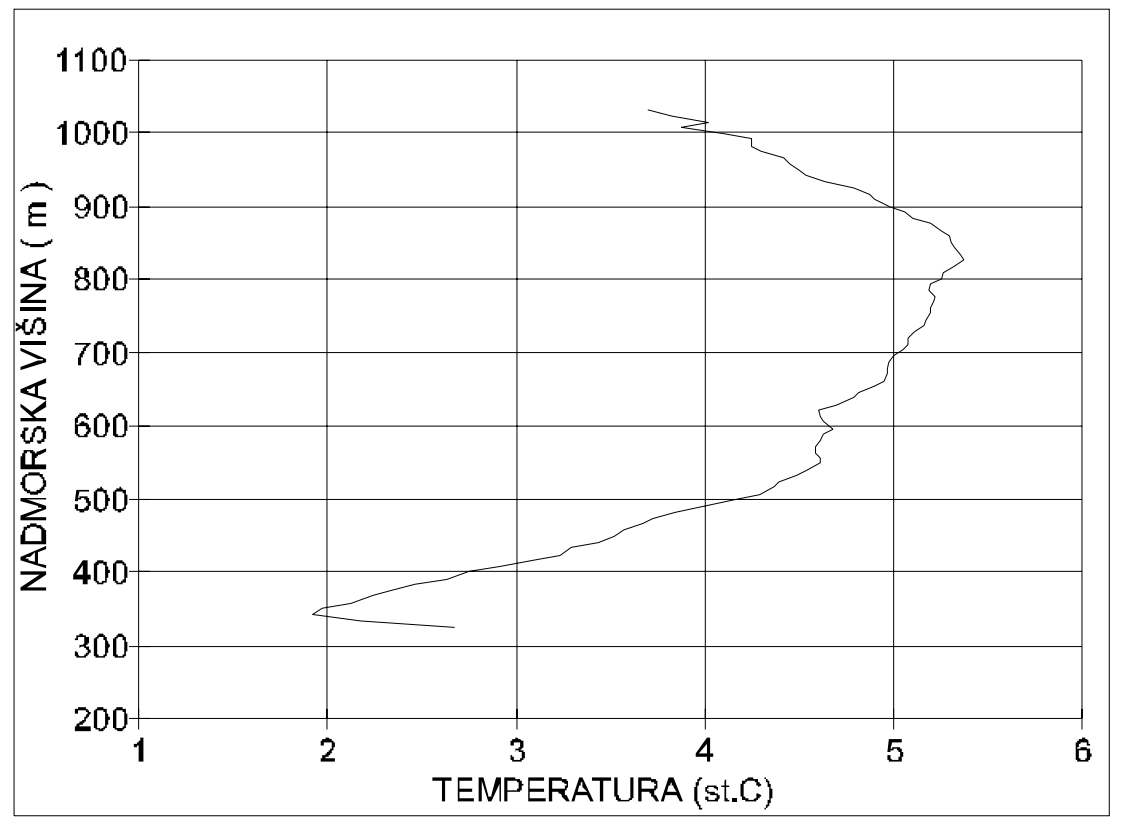

Slika 3 kaže povprečje vseh meritev. V 700 m visokem profilu je mogoče opaziti dve inverzni plasti. Manj intenzivna, ki se na naši sliki povprečnih vrednosti zabrisana $\mathrm{V}$ izotermni plasti se pojavlja na nadmorski višini 550 do $600 \mathrm{~m}$ (torej 250 do $275 \mathrm{~m}$ nad mestom). Druga inverzija je bolj izrazita in se pojavlja na višini 800 do $850 \mathrm{~m}$. V tem primeru gre za anticiklonalno (subsidenčno) inverzijo. Razlika med nahladnejšo in najtoplejšo točko $\mathrm{v}$ temperaturnem profilu je $\mathrm{v}$ povprečju znašala skoraj $3.5^{\circ} \mathrm{C}$ (slika 3). Oglejmo si še, kako so se v odvisnosti od zračnih mas oz. vremenskega tipa spreminjali temperaturni profili nad Dravsko dolino med 3.12. in 11.12. 1994. V tem času se je ciklon začel umikati anticiklonu, katerega učinki so bili najbolj vidni okoli 6.12. Po tem dnevu je anticiklon pričel slabeti in se počasi umikal novo prihajajočemu ciklonu. V soboto 3.12.1994 se je s ciklonalnim vremenskim tipom temperatura zraka nad Dravsko dolino z višino zelo malo spreminjala. S krepitvijo anticiklona $\mathrm{v}$ naslednjih dnevih se je zračna plast ustalila, kar se je kazalo $\mathrm{v}$ precej intenzivnem obratu, ki je trajal vse do 9.12., z viškom 5.12., ko so razlike v temperaturah med dolino in zgornjo mejo inverzije dosegle vrednost $7^{\circ} \mathrm{C}$. Tega dne so bile v Mariboru zabeležene tudi najvišje koncentracije $\mathrm{SO}_{2} \mathrm{v}$ kurilni sezoni 19941995: kar $131 \mathrm{ug} / \mathrm{m}^{3}$. Ta dan je bil tudi edini dan s preseženo mejno koncentracijo 
$\mathrm{SO}_{2} \mathrm{v}$ tej kurilni sezoni. $\mathrm{V}$ naslednjih dneh je zaradi slabitve anticiklona in večje prevetrenosti temperaturni obrat oslabel. 11.12. se je tako pojavljala le v šibki obliki s spodnjo plastjo na okoli $500 \mathrm{~m}$ nadmorske višine. Temu primeren je bil tudi padec koncentracij $\mathrm{SO}_{2}$, saj so 11.12. srednje dnevne koncentracije znašale le še $49 \mathrm{ug} / \mathrm{m}^{3}$.

\section{VIRI IN LITERATURA}

1. Arhiv HMZ, RS, Ljubljana, 1998

2. Barry R.G., Chorley R.J., 1992: Atmosphere, Weather \& Climate. Routledge, London.

3. Bernot F., 1978: Klima Zgornjega Posočja. 10.zborovanje slovenskih geografov, Ljubljana.

4. Enciklopedija Slovenije, 4.zvezek: geslo Temperaturni obrat. Mladinska knjiga, Ljubljana, 1990.

5. Furlan D., 1965: Temperature v Sloveniji. SAZU, Ljubljana.

6. Gams I., 1982: Temperaturni obrat in navpični gradienti v Slovenjegraški kotlini. GV, LIV, Ljubljana.

7. Gams I., 1996: Termalni pas v Sloveniji. GV, LXVIII, Ljubljana.

8. Heyer E., 1993: Witterung und Klima. B.G. Teubner Verlagsgesellschaft, Stuttgart, Leipzig.

9. Hočevar A, Petkovšek Z., 1995: Meteorologija. BTF, Ljubljana.

10. Hočevar A., 1966: Prikaz vremena nekaterih krajev Slovenije z lokalnimi vremenskimi tipi. Razprave, VII, Ljubljana.

11. Pučnik J., 1972: Temperaturne inverzije v Ljubljanski kotlini. Razprave, XIV, Ljubljana.

12. Schönwiese C.-D., 1994: Klimatologie. Verlag Eugen Ulmer, Stuttgart.

13. Šegota T., 1988: Klimatologija za geografe. Školska knjiga, Zagreb.

14. Žiberna I., 1996: Mestna klima Maribora. Doktorska disertacija, Oddelek za geografijo, Filozofska fakulteta, Ljubljana. 
Slika 1: Srednje minimalne mesečne temperature in relativna višina $\mathrm{v}$ Ljubljanski kotlini

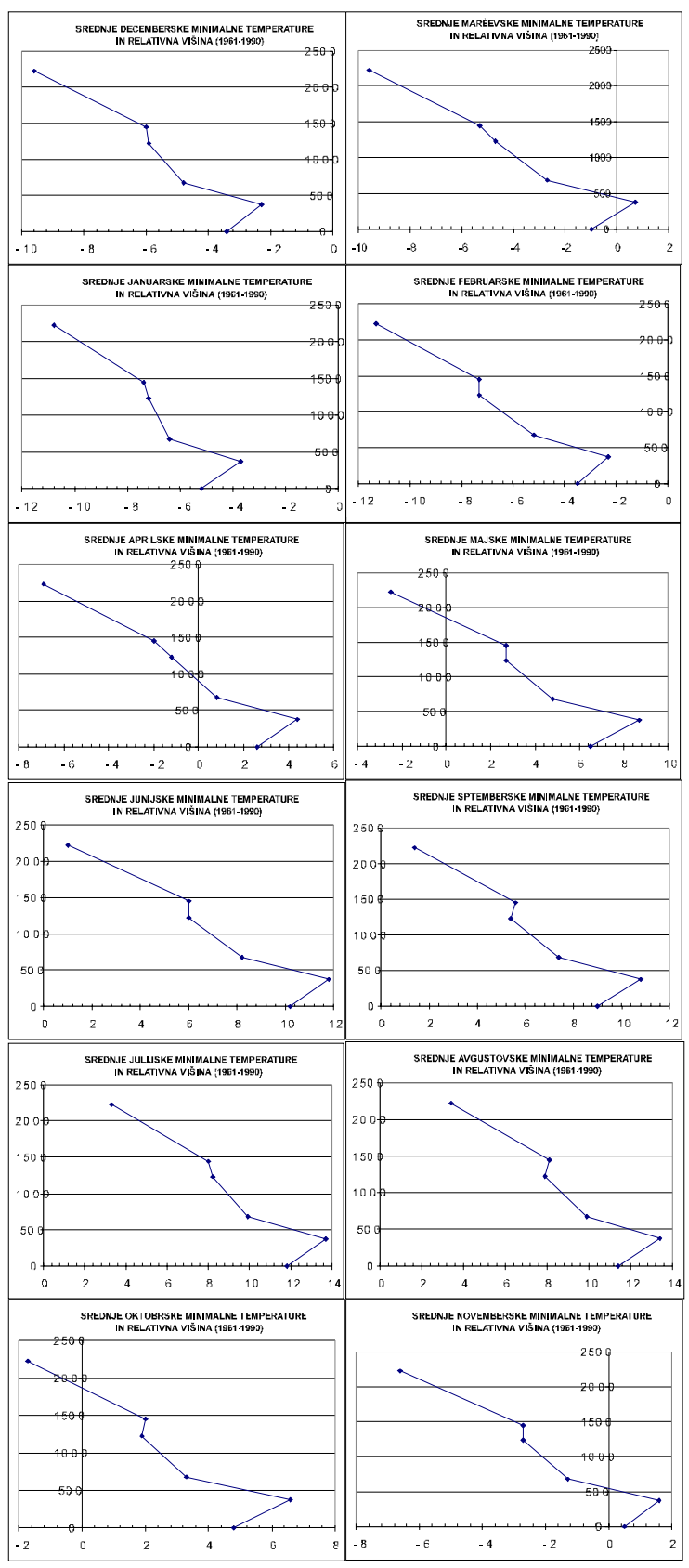


Slika 2: Srednje minimalne mesečne temperature in relativna višina v Bovški kotlini

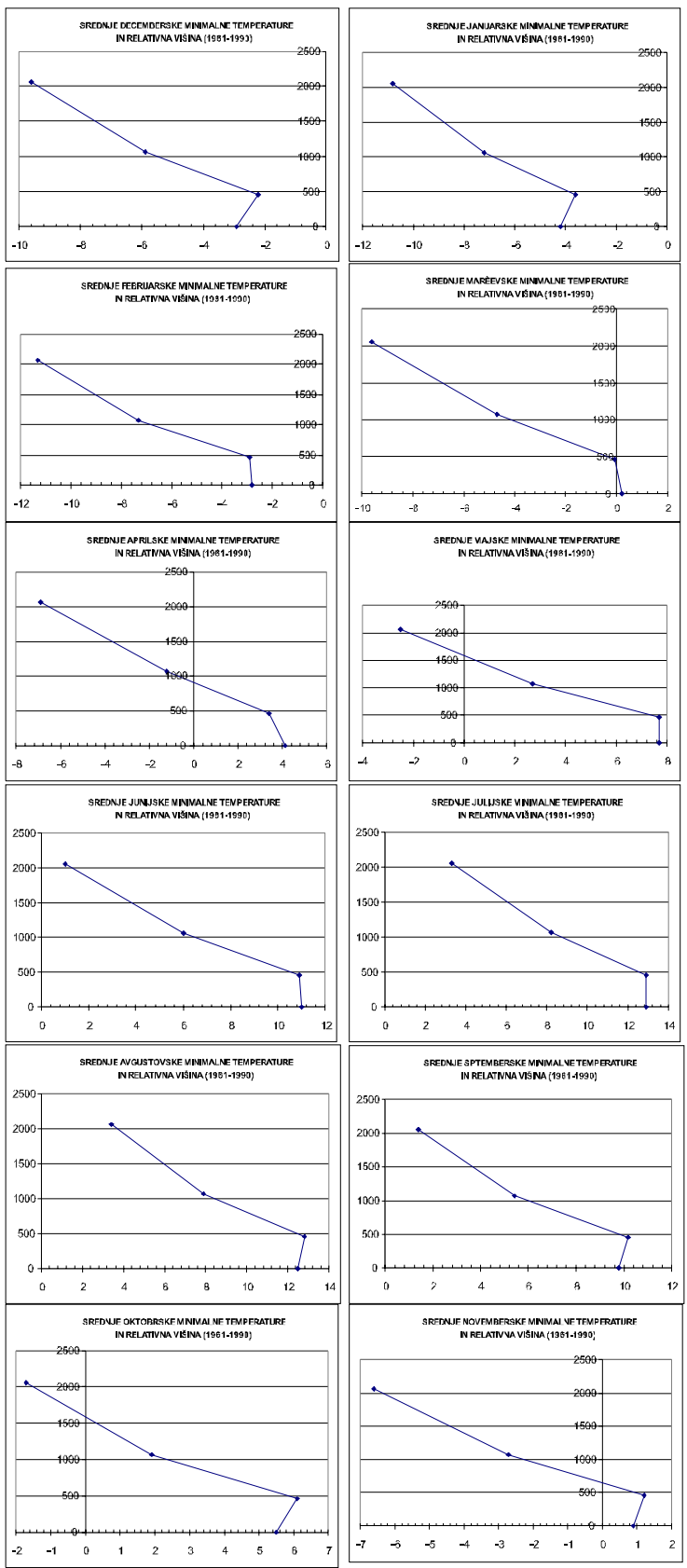




\title{
TEMPERATURE INVERSION IN MID-ALTITUDE REGIONS OF
}

\section{SLOVENIA}

\begin{abstract}
Summary
Temperature inversion is a regular phenomenon in valleys and basins in mountainous Slovenia. The near ground temperature inversion is the most expressive in the morning time and in winter, although it is possible in other months of the year as well. Other types of inversion are more binded on the sinoptic situation (anticyclons, front passages and the advection of warm or cold air masses in different altitudes). The datas show, that the altitude and the intesity of temperature inversions do not depend only by the weather types, but that the relief in this case plays an important modification role indeed. There is a possibility of two on time types of inversion.

In the article are shown only certain general characteristics of the appearance the inversion in different parts of mountainous Slovenia. We believe, that in the context would be necessary to direct the attention on the mechanism rising the inversion and for this purpose elaborate a genetic typisation of temperature inversions in Slovenia. This typisation could show a good basis for forecasting the altitude and the intensity of temperature inversion, which could be useful for forecasting low temperatures, high concentrations of pollutant gaseous in the air etc.
\end{abstract}

